\title{
Gene expression modifications in the liver caused by binge drinking and $S$-adenosylmethionine feeding. The role of epigenetic changes
}

\author{
Jun Li $\cdot$ Fawzia Bardag-Gorce $\cdot$ Joan Oliva $\cdot$ \\ Jennifer Dedes $\cdot$ Barbara A. French . \\ Samuel W. French
}

Received: 24 July 2009/Accepted: 22 October 2009/Published online: 4 December 2009

(C) Springer-Verlag 2009

\begin{abstract}
Chronic ethanol ingestion, achieved by feeding ethanol at a constant rate using intragastric tube feeding, alters the expression of genes in the liver. This is done by epigenetic mechanisms, which depend on the blood alcohol levels at the time of killing. However, acute bolus feeding of ethanol changes gene expression without lasting epigenetic changes. This occurs with histone 3 methylation and acetylation modifications. The gene expression response to an acute bolus of ethanol might be modified by feeding $S$-adenosylmethionine (SAMe), a methyl donor. In the present study, rats were given a bolus of ethanol $(6 \mathrm{~g} / \mathrm{kg}$ body weight (bw), SAMe (1 g/kg bw), ethanol + SAMe, or isocaloric glucose. The group of rats $(n=3)$ were killed at 3 and $12 \mathrm{~h}$ post bolus, and gene microarray analysis was performed on their liver cells. SAMe reduced the $3 \mathrm{~h}$ blood ethanol levels and increased the ALT levels at $3 \mathrm{~h}$. Venn diagrams showed that alcohol changed the expression of 646 genes at $3 \mathrm{~h}$ post bolus and 586 genes at $12 \mathrm{~h}$. SAMe changed the expression of 1,012 genes when fed with ethanol $3 \mathrm{~h}$ post ethanol bolus and 554 genes at $12 \mathrm{~h}$ post ethanol bolus. SAMe alone changed the expression of 1,751 genes at $3 \mathrm{~h}$ and 1,398 at $12 \mathrm{~h}$. There were more changes in gene expression at $3 \mathrm{~h}$ than at $12 \mathrm{~h}$ post ethanol when ethanol alone was compared to the dextrose control. The same was true when SAMe was compared to $\mathrm{SAMe}+$ ethanol. Ethanol up regulated gene expression in most functional pathways at $3 \mathrm{~h}$. However, when SAMe was fed with ethanol at $3 \mathrm{~h}$, most pathways were down regulated. At $12 \mathrm{~h}$, however, when ethanol was fed, the
\end{abstract}

J. Li · F. Bardag-Gorce $\cdot$ J. Oliva - J. Dedes .

B. A. French $\cdot$ S. W. French $(\bowtie)$

LABioMed Research Institute at Harbor-UCLA Medical Center,

1000 W. Carson St., Los Angeles, CA 90509, USA

e-mail: french7@ucla.edu pathways were half up regulated and half down regulated. The same was true when SAMe + ethanol was fed. The expression of epigenetically important genes, such as BHMT and Foxn3, was up regulated $3 \mathrm{~h}$ post alcohol bolus. At $3 \mathrm{~h}$, SAMe down regulated the expression of genes, such as BHMT, Mat2a, Jun, Tnfrs9, Ahcy 1, Tgfbr1 and 2, and Pcaf. At $12 \mathrm{~h}$, the insulin signaling pathways were half down regulated by ethanol, which was partly prevented by SAMe. The MAPK pathway was up regulated by ethanol, but SAMe did not prevent this. In conclusion, profound changes in gene expression evolved between $3 \mathrm{~h}$ and 12 post ethanol bolus. SAMe down regulated these changes in gene expression at $3 \mathrm{~h}$, and less so at $12 \mathrm{~h}$.

Keywords Binge drinking - Epigenetic memory . Methyl donor $\cdot S$-adenosylmethionine

\section{Introduction}

Characteristically, it takes many years of alcohol abuse before alcoholic liver disease becomes manifest. Shortterm binge drinking does not induce liver injury beyond a transient fatty liver. The question then is what changes occur in the liver that would explain the switch from transient fatty liver to progressively severe liver damage, culminating in cirrhosis and eventually, in some cases, to hepatocellular carcinoma. Recently, evidence for the role of epigenetic memory has emerged as a phenomenon, which could be a factor in the progression from transient fatty liver to more advanced alcoholic liver diseased. Data indicates that the changes in gene expression, observed after binge drinking, differ considerably from those observed after chronic ethanol ingestion in the rat intragastric feeding model of alcohol liver disease [1]. 
Comparisons of gene microarray analyses between the acute and chronic models, including high and low blood alcohol levels, showed little homology [1]. Gene expression was mainly up regulated 3 and $12 \mathrm{~h}$ after an acute bolus of ethanol. After 1 month of continuous ethanol feeding ( $13 \mathrm{~g} / \mathrm{kg}$ body weight/day), gene expression was similar to controls at low blood alcohol levels, but markedly up regulated when blood alcohol levels were high. This indicated that the gene expression program had changed to adapt to ethanol. But at high blood alcohol levels, this adaptation program was over ridden due to epigenetic changes in gene transcription regulation not evident during binge drinking. The epigenetic changes present during chronic ethanol feeding, not present during binge drinking, included an increase in H3K18ac, which activates gene expression; an increase in $\mathrm{H} 3 \mathrm{~K} 27 \mathrm{me} 3$, which silences gene expression; an increase in $\mathrm{H} 3 \mathrm{~K} 9 \mathrm{ac}$, which activates gene expression; and an increase in H3K4me2, which activates gene expression [1, 2]. Two enzymes, involved in epigenetic changes, were increased after chronic feeding: (1) p300 protein levels were increased after chronic ethanol feeding [2]. p300 is a histone acetyltransferase (HAT) that acetylates histones, which leads to the activation of gene expression [2]; (2) Sirt1, a deacetylase, was increased after chronic ethanol feeding [1-3]. Deacetylation of histones leads to inactivation of gene expression. The role of epigenetic reprogramming of gene expression in the liver in response to ethanol feeding has recently been reviewed [4].

In the present study, $S$-adenosylmethionine (SAMe), a methyl donor, was fed with a bolus of ethanol to find out if DNA/Histone methylation would prevent the changes in gene expression during binge drinking in the rat. In a prior study on mice acutely fed a liver toxin, SAMe feeding prevented the toxic effects of the drug by preventing demethylation of histones [5]. Therefore, we expected that SAMe donation of methyl groups to methylate histones would silence gene expression that normally would be up regulated by binge drinking [1].

\section{Methods}

Animal model of alcoholic liver disease

Male Wistar rats from Harleco (Hollister, CA), weighing 250-300 g, were used. The rats from a previously reported study [1] (number 3-4/group) were fed acutely an alcohol bolus of ethanol by gavage $(6 \mathrm{~g} / \mathrm{kg}$ body weight, $20 \%$ solution). Controls were fed isocaloric glucose. The rats were killed 3 or $12 \mathrm{~h}$ after the alcohol feeding. A second group of rats was fed $S$-adenosylmethionine (SAMe) $(1 \mathrm{~g} / \mathrm{kg}$ body wt) by gavage with ethanol $(6 \mathrm{~g} / \mathrm{kg})$ or isocaloric dextrose, and killed at 3 or $12 \mathrm{~h}$ (Table 1). Urine and blood were collected at killing to measure alcohol levels. Blood ALT levels were also measured. Liver tissue was quick frozen in isopentane in liquid nitrogen, and gene microarray analysis was done on RNA extracted from the fast frozen tissue. Liver tissue was also fixed in $10 \%$ zinc formalin for H\&E staining. Microarray results were obtained and were compared with microarrays done on liver tissue from previously reported studies [1]. The urine was collected under toluene to prevent evaporation using metabolic cages (one rat/cage). The urinary alcohol level was measured using a QED Saliva Alcohol A 150 test kit STC Technologies, (Bethlehem, PA). Blood alcohol and alanine aminotransferase (ALT) were measured using a chemical analyzer. At killing under isofluorane anesthesia, the liver was removed and weighed. A portion of the livers were quick frozen and stored in isopentane in liquid nitrogen, followed by storage at $-80^{\circ} \mathrm{C}$. The rats were maintained according to the Guidelines of Animal Care, as described by the National Academy of Sciences and published by the National Institute of Health (1996).

Table 1 Effects of acute ethanol treatment ( $6 \mathrm{~g} / \mathrm{kg}$ body weight, bolus) at 3 and $12 \mathrm{~h}$, with and without SAMe

\begin{tabular}{|c|c|c|c|c|c|c|}
\hline Treatment & $\begin{array}{l}\text { Time } \\
\text { (h) }\end{array}$ & $\begin{array}{l}\text { UAL } \\
(\mathrm{mg} \%)\end{array}$ & $\begin{array}{l}\text { BAL } \\
(\mathrm{mg} \%)\end{array}$ & $\begin{array}{l}\text { ALT } \\
\text { (U/L) }\end{array}$ & Path score & $N$ \\
\hline Ethanol & 3 & $453.33 \pm 56.66$ & $347.86 \pm 68.03$ & $50.75 \pm 2.9$ & 0 & 4 \\
\hline Dextrose & 3 & 0 & 0 & $41.25 \pm 3.1$ & 0 & 4 \\
\hline Ethanol & 12 & $33.4 \pm 15.5$ & $29 \pm 17.39$ & $54 \pm 3.2$ & 0 & 3 \\
\hline Dextrose & 12 & 0 & 0 & $50 \pm 4$ & 0 & 3 \\
\hline Ethanol + SAMe & 3 & $123 \pm 48$ & $138 \pm 60$ & $142 \pm 67$ & 0 & 3 \\
\hline Dextrose + SAMe & 3 & 0 & 0 & $50 \pm 4$ & 0 & 3 \\
\hline Ethanol + SAMe & 12 & $51 \pm 24$ & $39 \pm 63$ & $66 \pm 24$ & 0 & 3 \\
\hline Dextrose + SAMe & 12 & 0 & 0 & $62 \pm 32$ & 0 & 3 \\
\hline
\end{tabular}

Note that SAMe reduced the $3 \mathrm{~h}$ blood alcohol levels, and increased the $3 \mathrm{~h}$ ALT levels, when compared to the dextrose controls. The alcohol + dextrose treated results are reprinted from Bardag-Gorce et al. [1], with permission from WILEY InterScience 
Microarray analysis

Liver tissues from rats fed ethanol, SAMe, or dextrose were subjected to microarray analysis. Total liver RNAs were extracted with Ultraspec ${ }^{\mathrm{TM}}$ RNA Isolation Systemic (Biotecx Laboratories, Houston, TX), and were cleaned up with Rneasy columns (Qiagen, Valencia, CA). Microarray analyses, performed on rats fed ethanol alone, were taken from a previously reported study [1]. Five micrograms of total RNA were used for preparing biotin-labeled cRNA. Labeled and fragmented cRNA was subsequently hybridized to rat or human Genome Array (Affymetrix, Santa Clara, CA). Labeling, hybridization, image scanning, and initial data analysis were performed at the Microarray Core at Los Angeles Biomedical Research Institute. For sample preparation and loading, an equal amount of RNA (5 $\mu \mathrm{g}$ each) from each sample was used for Affymetrix GeneChip analysis. RNA was converted to cDNA using GeneChip ${ }^{\circledR}$ OneCycle cDNA Synthesis Kit (Affymetrix, Santa Clara, CA), and then converted to biotinylated cRNA using GeneChip ${ }^{\circledR}$ IVT Labeling Kit (Affymetrix, Santa Clara, CA). The quality of labeled RNA was confirmed with the Affymetrix or Test 3 Array. The biotinylated cRNA from all samples was hybridized to Affymetrix Rat GeneChip arrays. To perform the hybridization and staining, the hybridization cocktail was prepared, which included controls of the fragmented cRNA. The samples were hybridized in the array at $45^{\circ} \mathrm{C}$ for $17 \mathrm{~h}$ using GeneChip Hybridization Oven 640. Immediately following hybridization, the array underwent an automated washing and staining protocol (R-Phycoerythin Streptavidin conjugated, Molecular Probes, Invitrogen Corp., Carlsbad, CA) on the GeneChip Fluidics Station 400. The array was then scanned with a GeneChip Scanner 3000 (Affymetrix, Santa Clara, CA).

Data preparation, analysis, and integration were performed using Affymetrix's GeneChip Operating Software (GCOS). The software was used to perform image processing, evaluation of data quality, normalization, transformation, and filtering, so that data would be ready for further analysis. Wilcoxon's signed rank test was used in comparison analysis to derive biologically significant results from the raw probe cell intensities on expression arrays. For comparison analysis, each probe set on the experiment array was compared with its counterpart on the control array to calculate the change in $P$ value used to generate the difference call of increase (I; $P<0.04$ ), marginal increase (MI; $P<0.04$ to $P<0.06$ ), decrease (D; $P>0.997$ ), marginal decrease (MD; $P>0.992$ to $P>0.997$ ), or no change (NC: $P>0.06$ to $P<0.997)$. Comparison analysis was used to generate a signal $\log$ ratio for each probe prior to the experimental array to the corresponding probe pair on the control array. This strategy cancels out differences resulting from different probe finding coefficients. Signal log ratio was computed by using a one-step Tukey's biweight method by taking a mean of the log ratio of probe pair intensities across the two arrays.

Once the absolute and comparison data files were created in GCOS, genes were identified with signal intensity differences using BULLFROG v12.3 TG Lockhart and Lockhart, (San Diego, CA) and GeneSpring Silicon Genetics, Agilent Technologies, (Santa Clara, CA). In the BULLFROG analysis, the pair-wise comparisons were used to find consistent differences among all of the samples compared. The criteria used were as follows: a change call of increase/marginal increase or decrease/marginal decrease, fold change $>1.7$, and a present call in at least one of the arrays. In GeneSpring, the probes were first normalized using "Peer Gene: Normalize to median." Next, transcripts were determined to be differentially expressed based on the following criteria: a change call of increase, marginal increase, decrease, or marginal decrease with a change $P$ value $<0.006$ or $>0.994$, a signal log ratio $<-0.8$ or $>0.8$, a present call for the probe set in either or both experimental conditions, and a minimum signal intensity of 50 of a probe in either or both of the experimental files.

After generating a list of differentially expressed genes, down stream analysis was performed. The filtered transcripts were clustered in GeneSpring using SOM, K-means, and GeneTree to find similar patterns of gene expression. The lists of transcripts were also uploaded into GenMapp (Gene MicroArray Pathway Profiler, Gladstone Institutes University of California at San Francisco). GenMapp clusters the transcripts based on biological function.

The data illustrated were obtained by using the KEGG web site (http://www.genome.ip/kegg/pathway.html) and blasting the list of total changed genes issued from our experiment for analysis. The website calculates the number of up regulated and down regulated genes for each pathway shown in the KEGG graph. To determine the percent gene change in each pathway, the number of changed genes present in each pathway was divided by the total number of genes in the same pathway.

The same calculation was performed in the ABI panther website (http://www.pantherdb.org/genes) to illustrate the pie chart. To determine the percent gene change in each pathway, the number of genes present in each pathway was divided by the total number of changed genes.

\section{Results}

Animal feeding experiment (Table 1)

The effect of $S$-adenosylmethionine (SAMe) on the acute ethanol bolus was measured. Eight groups of rats were 
studied $(n=3)$, i.e., (ethanol + SAMe; dextrose + SAMe $3 \mathrm{~h}$ ); (ethanol + SAMe; dextrose + SAMe $12 \mathrm{~h}$ ); (ethanol or dextrose $3 \mathrm{~h}$ ); (ethanol or dextrose $12 \mathrm{~h}$ ) (see Table 1).

Microarray analysis

Microarray analysis of the 3 and $12 \mathrm{~h}$ post ethanol bolus showed changes in the expression of 646 genes at $3 \mathrm{~h}$ and 586 genes at $12 \mathrm{~h}$ (Venn diagram) (Fig. 1). A total of 540 genes were unique to $3 \mathrm{~h}$ and 480 were unique to $12 \mathrm{~h}$.

At $3 \mathrm{~h}$ post ethanol bolus, SAMe changed the expression of 1,751 genes, when compared to the dextrose controls (Fig. 1). Ethanol + SAMe at $3 \mathrm{~h}$ changed the expression of 646 genes when compared with dextrose, and 1,012 genes when compared to ethanol alone (Fig. 1).

At $12 \mathrm{~h}$ post ethanol bolus, SAMe changed the expression of 1,398 genes, when compared with dextrose controls, and ethanol + SAMe changed the expression of 554 genes, when compared to ethanol alone. Ethanol changed the expression of 586 genes, when compared to the dextrose controls (Fig. 1). Note that there were more changes in gene expression after $3 \mathrm{~h}$ post ethanol bolus than after $12 \mathrm{~h}$. This was true for the effect of SAMe alone, ethanol alone, and ethanol + SAMe.

When the effects of ethanol and SAMe on functional pathways were analyzed using KEGG, many differences were found when compared to the dextrose controls. KEGG functional pathway changes $3 \mathrm{~h}$ after acute ethanol bolus showed mainly increased gene expression (red) for all but three pathways (Fig. 2).

When SAMe was fed with ethanol $3 \mathrm{~h}$ post ethanol bolus, changes in gene expression were largely decreased in almost all pathways (green) (Fig. 3). This shows that the effect of SAMe prevented the effect of ethanol on gene expression at $3 \mathrm{~h}$.
Fig. 1 Venn diagrams comparing the changes in gene expression when ethanol was fed with or without SAMe treatment, 3 and $12 \mathrm{~h}$ post ethanol bolus $(n=3)$
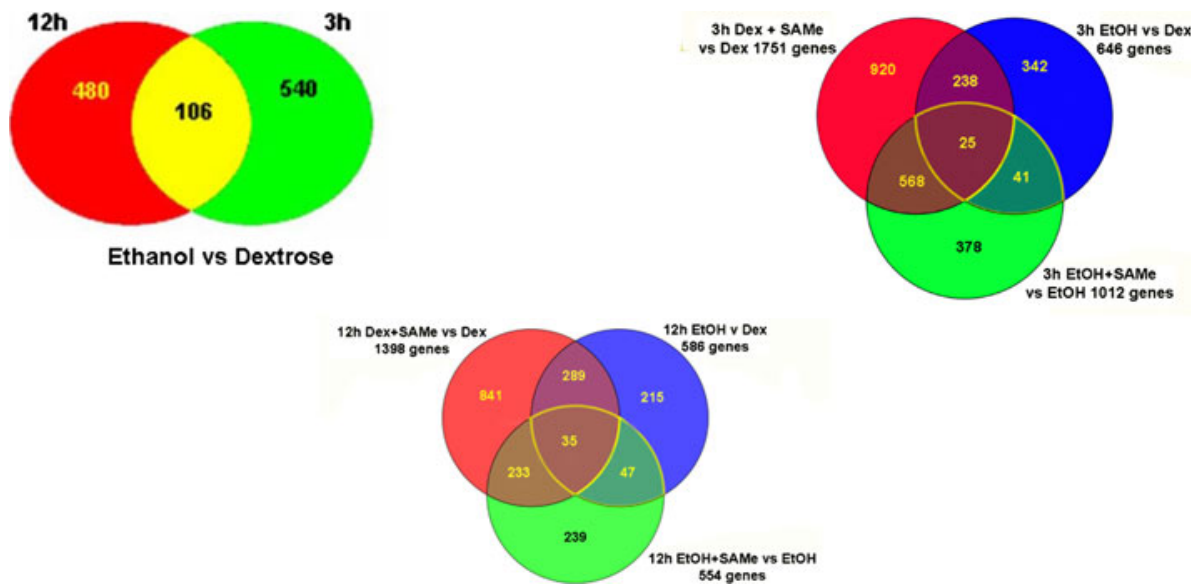

554 genes

Fig. 2 KEGG functional pathway changes in gene expression induced by $3 \mathrm{~h}$ post $6 \mathrm{~g} / \mathrm{kg}$ ethanol bolus $(n=3)$. The changes affect almost all pathways. Red is up regulated and green is down regulated. These results are reprinted from Bardag-Gorce et al. [1], with permission from WILEY InterScience

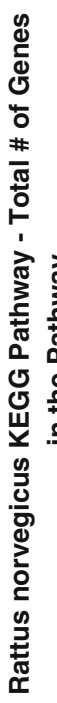

3h Ethanol vs $3 \mathrm{~h}$ Control

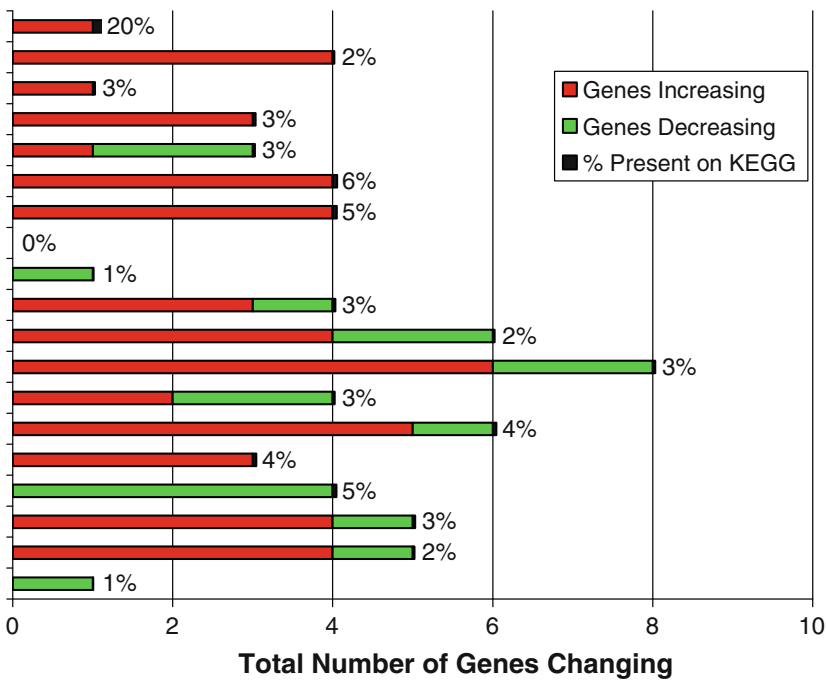


Fig. 3 KEGG functional pathways showed that SAMe feeding with an ethanol bolus negated the effects of ethanol because the changes in gene expression were mainly decreased (green) not increased (red) $(n=3)$
Fig. 4 KEGG functional pathways are shown. $3 \mathrm{~h}$ post SAMe was compared to dextrose controls. Note that the great majority of changes in gene expression were down regulated by SAMe (green) $(n=3)$

\section{3h Ethanol+SAMe vs $3 \mathrm{~h}$ Ethanol}
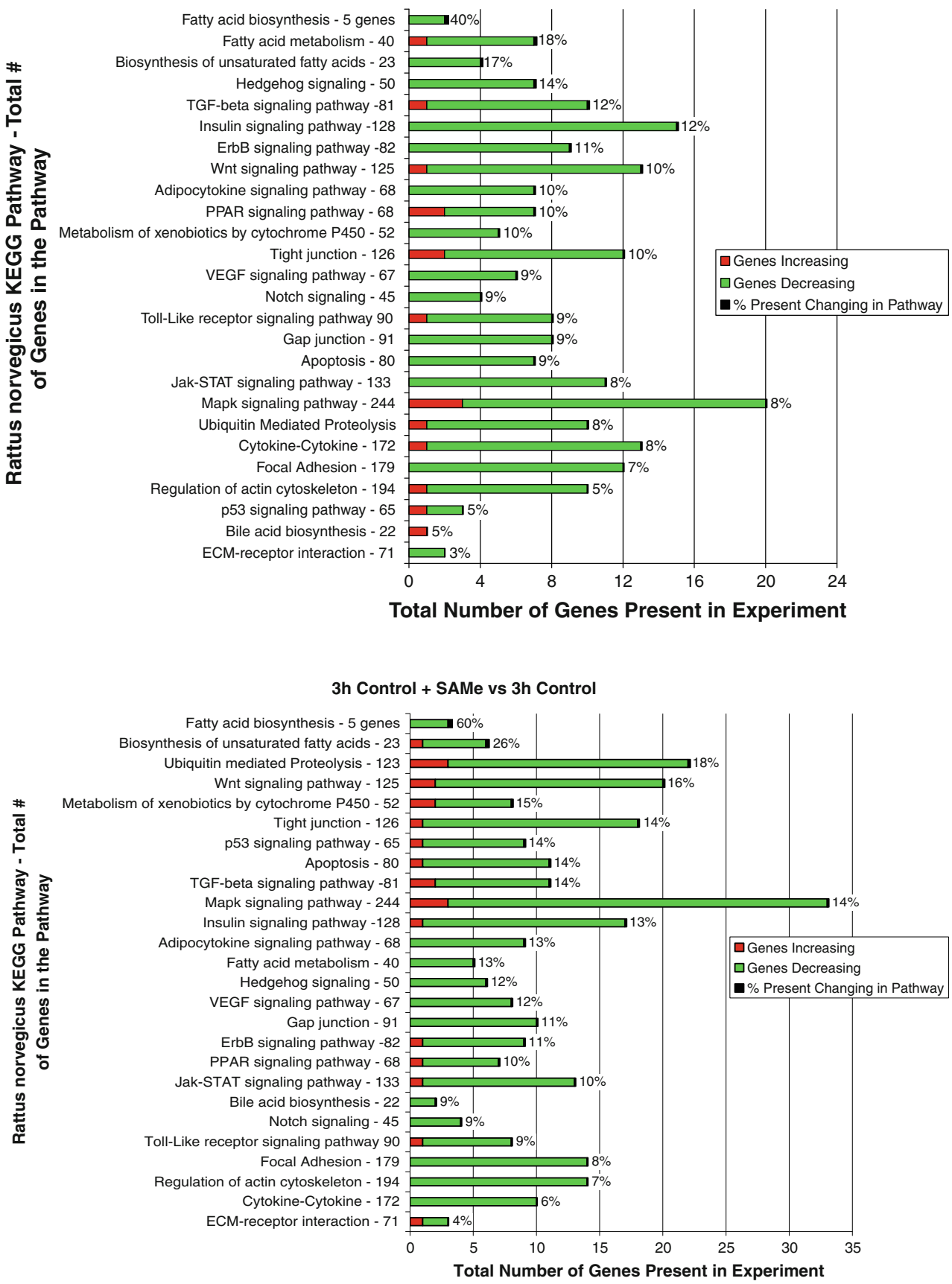

When the KEGG functional pathways were compared between SAMe + dextrose vs. dextrose control at $3 \mathrm{~h}$ post bolus, SAMe decreased the gene expression to a large extent compared to controls (green) (Fig. 4).

$12 \mathrm{~h}$ after the acute ethanol bolus, there was an increase in almost all but one pathway, and, additionally, there was an increase in the number of genes that were down regulated (Fig. 5). The KEGG functional pathways showed that the gene expression changes induced by ethanol $12 \mathrm{~h}$ post ethanol bolus were about half up regulated and half down regulated with the exception of the MAPK pathway, which was mostly up regulated, and the insulin signaling pathway, which was mostly down regulated (Fig. 5).

The KEGG functional pathways from $12 \mathrm{~h}$ post ethanol + SAMe livers showed that gene expression changes induced by SAMe were half up regulated and half down regulated when compared to the ethanol fed controls (Fig. 6).

The KEGG functional pathways of rats fed dextrose + SAMe, $12 \mathrm{~h}$ post SAMe bolus showed that the 


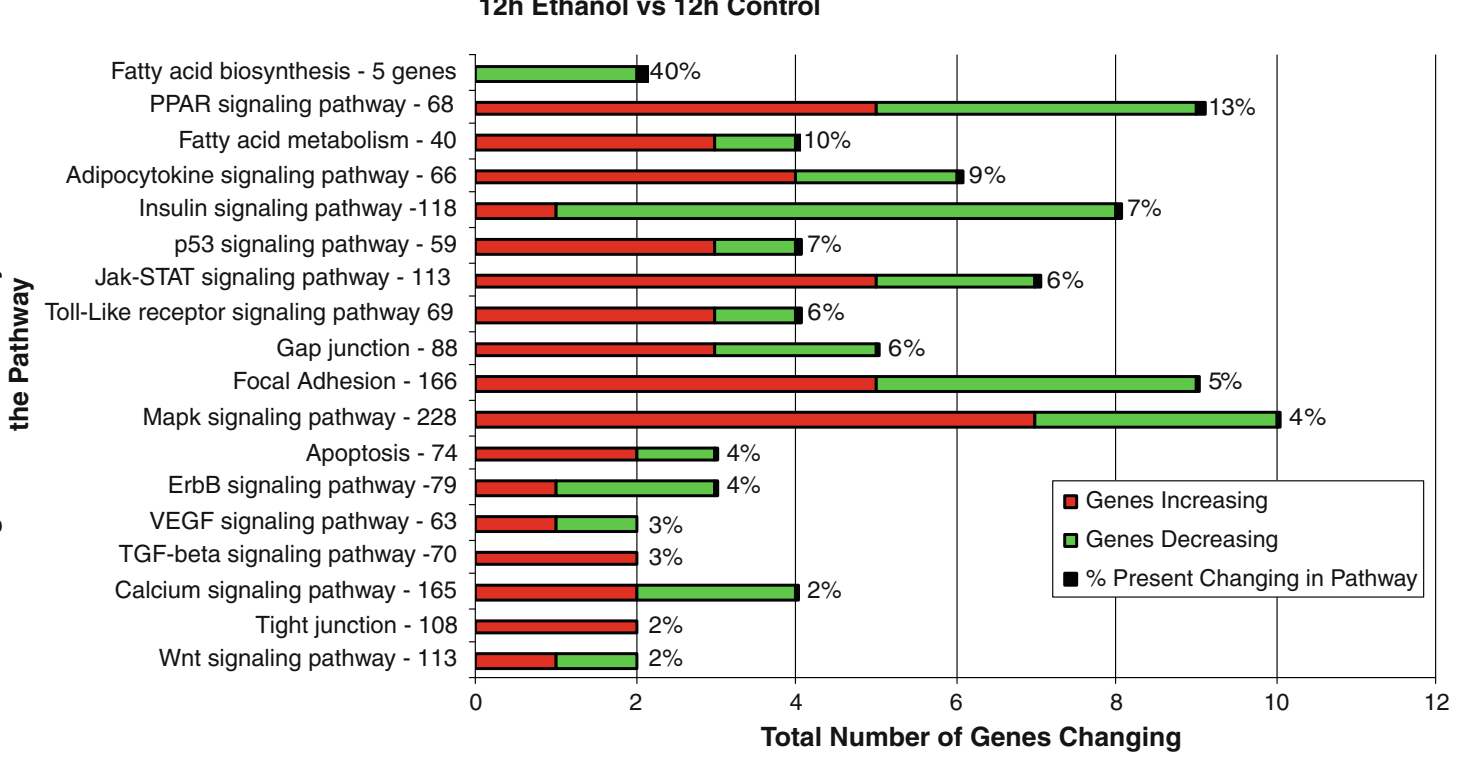

Fig. 5 KEGG functional pathways $12 \mathrm{~h}$ post ethanol bolus compared to the dextrose fed control. (Red up regulated, Green down regulated) $(n=3)$. These results are reprinted from Bardag-Gorce et al. [1], with permission from WILEY InterScience

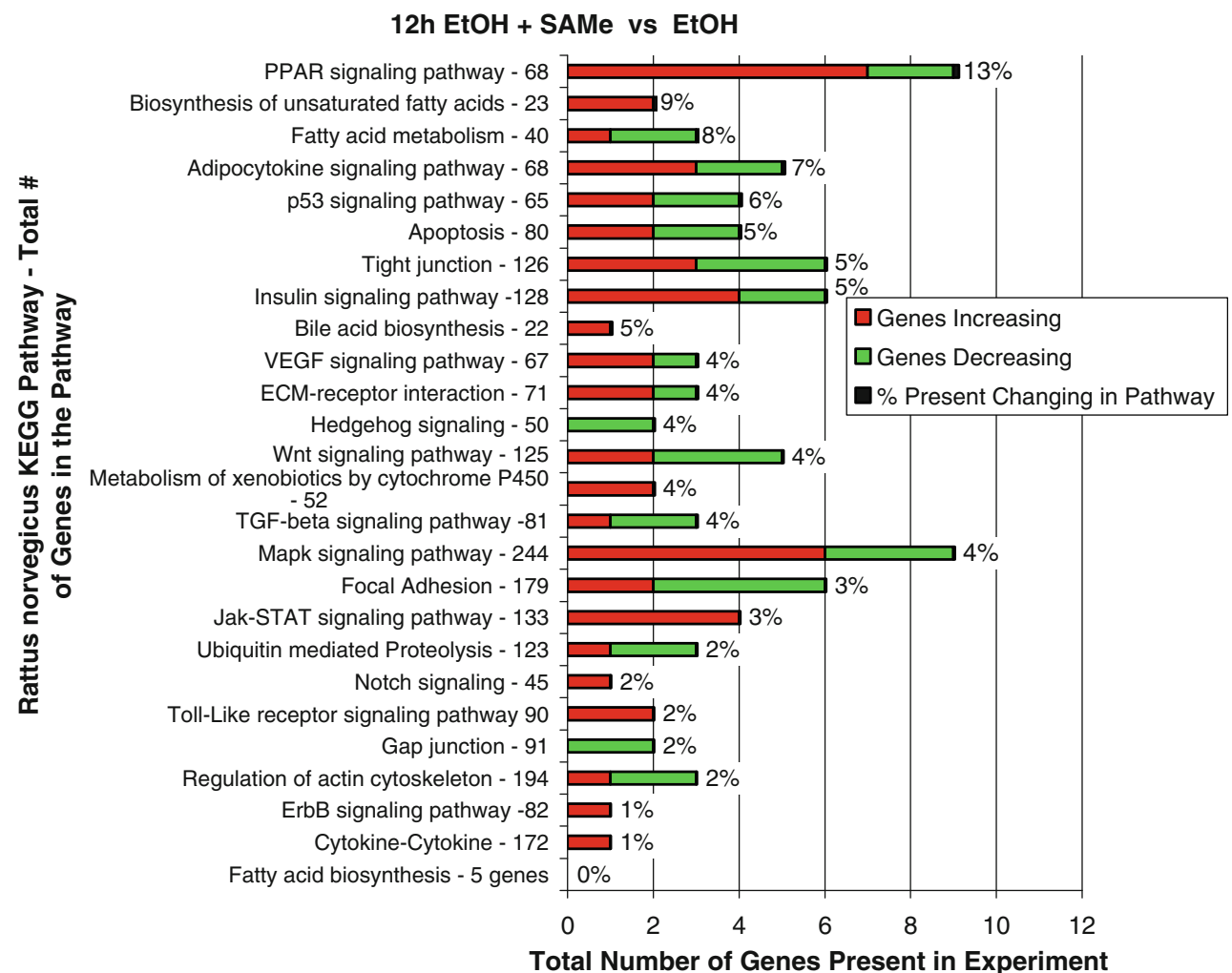

Fig. 6 KEGG functional pathways $12 \mathrm{~h}$ post ethanol bolus where SAMe feeding with ethanol was compared to ethanol fed alone $(n=3)$. The PPAR signaling pathway and the Jak-STAT signaling

gene expression changes induced by SAMe were mainly up regulated compared to the dextrose controls (Fig. 7). pathway were mainly up regulated (red). The results are quite different from $3 \mathrm{~h}$ post ethanol bolus where SAMe down regulated most of the pathways that were up regulated by ethanol (see Fig. 3)

SAMe down regulated the changes in gene expression of individual genes induced by alcohol at $3 \mathrm{~h}$ (Table 2). SAMe also caused a down regulation of gene expression 
Fig. 7 The KEGG functional pathway gene expression changes by SAMe at $12 \mathrm{~h}$ post SAMe bolus were half up regulated and half down regulated $(n=3)$. This contrasted with $3 \mathrm{~h}$ post bolus where SAMe caused mostly down regulation of the pathways (see Fig. 3)

\section{2hr Dextrose + SAMe vs Dextrose}

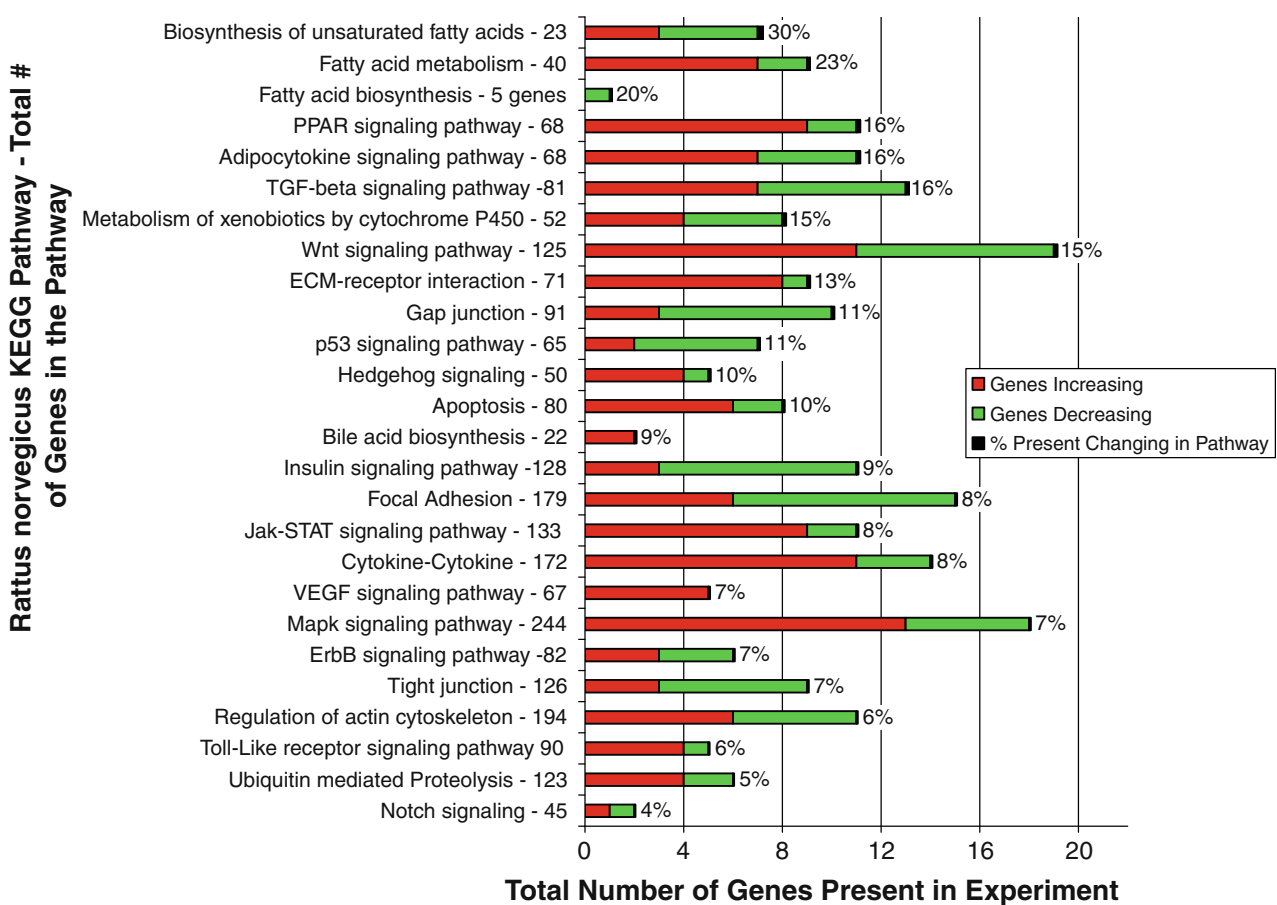

Table 2 Gene expression changes post $3 \mathrm{~h}$ ethanol bolus and the effects of SAMe on these changes

\begin{tabular}{|c|c|c|c|c|}
\hline \multirow[t]{2}{*}{ Gene symbol } & \multicolumn{3}{|l|}{ Ratio } & \multirow[t]{2}{*}{ Gene name } \\
\hline & $\begin{array}{l}\text { Alcohol + SAMe } \\
\text { vs. Alcohol }\end{array}$ & $\begin{array}{l}\text { SAMe } \\
\text { vs. Dextrose }\end{array}$ & $\begin{array}{l}\text { Alcohol } \\
\text { vs. Dextrose }\end{array}$ & \\
\hline Aldh6a1 & -1.79 & $\mathrm{nc}$ & $\mathrm{nc}$ & Aldehyde dehydrogenase 6 \\
\hline Igf $2 b p 3$ & -1.83 & -3.41 & 2.3 & Insulin-like growth factor binding protein \\
\hline Bhmt & -1.89 & $\mathrm{nc}$ & 1.7 & Betaine-homocysteine methyltransferase \\
\hline Cth & -2.31 & -1.97 & $\mathrm{nc}$ & Cystathionase \\
\hline Mat2a & -2.33 & -2.48 & $\mathrm{nc}$ & Methionine adenosyltransferase \\
\hline Fox n3 & -2.43 & $\mathrm{nc}$ & 2.0 & Foxhead box N3 \\
\hline Jun & -2.79 & -2.43 & $\mathrm{nc}$ & Jun oncogene \\
\hline Tnfrsf9 & -3.03 & -5.17 & $\mathrm{nc}$ & TNF receptor 9 \\
\hline Ahcyl & -3.16 & -2.46 & $\mathrm{nc}$ & S-adenosylmethyl transferase hydrolase \\
\hline Tgfbrl & -3.18 & -3.71 & $\mathrm{nc}$ & TGF beta receptor 1 \\
\hline Pcaf & -3.18 & $\mathrm{nc}$ & $\mathrm{nc}$ & p300/cBP associated factor \\
\hline Rxra & -3.19 & -2.35 & $\mathrm{nc}$ & Retinoid X receptor alpha \\
\hline Tgfbr2 & -12.3 & -6.82 & $\mathrm{nc}$ & TGF beta receptor \\
\hline Igf2r & $\mathrm{nc}$ & -1.77 & $\mathrm{nc}$ & $\mathrm{IgF} 2$ receptor \\
\hline Hzafy2 & $\mathrm{nc}$ & -2.31 & $\mathrm{nc}$ & H2A histone Y2 \\
\hline Srebfl & $\mathrm{nc}$ & -2.57 & $\mathrm{nc}$ & Sterol regulatory eleven binding factor \\
\hline Fasn & $\mathrm{nc}$ & -3.2 & $\mathrm{nc}$ & Fatty acid synthase \\
\hline Adh4 & $\mathrm{nc}$ & -3.29 & $\mathrm{nc}$ & Alcohol dehydrogenase 4 \\
\hline Foxa2 & $\mathrm{nc}$ & -3.32 & -3.39 & Foxhead box A2 \\
\hline FoxK2 & $\mathrm{nc}$ & -5.28 & $\mathrm{nc}$ & Foxhead box K2 \\
\hline HDAC2 & $\mathrm{nc}$ & $\mathrm{nc}$ & -1.9 & Histone deacetylase 2 \\
\hline FOXO1a & $\mathrm{nc}$ & $\mathrm{nc}$ & -2.1 & Foxhead box 1 a \\
\hline FOXOp1 & $\mathrm{nc}$ & -2 & $\mathrm{nc}$ & Foxhead box p1 \\
\hline
\end{tabular}


Table 3 Gene expression changes $12 \mathrm{~h}$ post ethanol bolus and the effects of SAMe on these changes

\begin{tabular}{|c|c|c|c|}
\hline \multirow[t]{2}{*}{ Gene symbol } & \multicolumn{2}{|l|}{ Fold change } & \multirow[t]{2}{*}{ Gene name } \\
\hline & $\begin{array}{l}\text { Alcohol + SAMe } \\
\text { vs. Alcohol }\end{array}$ & $\begin{array}{l}\text { Dextrose + SAME } \\
\text { vs. Dextrose }\end{array}$ & \\
\hline CYP1a1 & 7.84 & 8.11 & Cytochrome p450 1a1 \\
\hline CYP17A & 4.56 & 2.71 & Cytochrome p450 17A1 \\
\hline Cycl 1 & 4.06 & 15.67 & Chemokine legand 1 \\
\hline Gadd45b & 4.06 & 3.2 & Growth arrest and DNA damage $45 b$ \\
\hline CYP7a1 & 3.63 & $\mathrm{nc}$ & Cytochrome p450 7a 1 \\
\hline Gsta2 & 3.01 & -2 & Glutathionine S-transferase a2 \\
\hline Garld45g & 2.87 & $\mathrm{nc}$ & Growth arrest and DNA damage $45 \mathrm{q}$ \\
\hline Hmoxl & 2.51 & $\mathrm{nc}$ & Homogenase 1 \\
\hline Fabp4 & 1.58 & $\mathrm{nc}$ & Fatty acid binding protein 4 \\
\hline Mknk2 & 1.82 & $\mathrm{nc}$ & MAP kinase-threonine kinase 2 \\
\hline Adipor2 & 1.67 & 2.13 & Adiponectin receptor 2 \\
\hline Cth & -1.88 & 2.77 & Cystathionase \\
\hline Lepr & -2.71 & 9.58 & Leptin receptor \\
\hline Jak3 & $\mathrm{nc}$ & 3.03 & Janus kinase 3 \\
\hline Adhi & $\mathrm{nc}$ & 2.81 & Alcohol dehydrogenase 1 \\
\hline CYP4a1 & $\mathrm{nc}$ & 2.35 & Cytochrome p450 4a1 \\
\hline Stat3 & $\mathrm{nc}$ & 2.35 & Signal transdura activator transcription 3 \\
\hline Jun $b$ & $\mathrm{nc}$ & 2.1 & Jun B oncogene \\
\hline Timp2 & $\mathrm{nc}$ & 1.74 & Tissue inhibitor metalloproteinase 2 \\
\hline HAT1 & $\mathrm{nc}$ & -1.83 & Histone aminotransferase 1 \\
\hline Aldh5a1 & $\mathrm{nc}$ & -1.87 & Aldehyde dehydrogenase 5 \\
\hline FOXa2 & $\mathrm{nc}$ & -2.06 & Forehead box AZ \\
\hline Hdac2 & $\mathrm{nc}$ & -2.06 & Histone deacetylase 2 \\
\hline Bhmt & $\mathrm{nc}$ & -2.27 & Betaine homocysteine methyltransferase \\
\hline Ubd & $\mathrm{nc}$ & 2.41 & Ubiquitin D \\
\hline Aldh1b1 & $\mathrm{nc}$ & 2.41 & Aldehyde dehydrogenase 1 \\
\hline
\end{tabular}

compared to the dextrose controls at $3 \mathrm{~h}$ (Table 2). In contrast, most of the genes, which were listed in Table 2, were unchanged by alcohol and in some cases down regulated.

SAMe failed to prevent the change in expression of many genes at $12 \mathrm{~h}$ (Table 3 ). The down regulation of gene expression, caused by SAMe at $3 \mathrm{~h}$, failed to occur at $12 \mathrm{~h}$ (Table 3). These results correlate with the overall global changes shown by the Venn diagrams and with the KEGG functional pathways (Figs. 2, 3, 4, 5, 6, 7, and 8). In conclusion, the effect of SAMe on alcohol induced gene expression is mainly found at $3 \mathrm{~h}$ post ethanol bolus and not at $12 \mathrm{~h}$.

In order to show the gene expression at $12 \mathrm{~h}$ post ethanol bolus vs. the control, selected genes were compared (Table 4). The genes that were up regulated at $3 \mathrm{~h}$ post alcohol bolus (Table 2) were different compared to $12 \mathrm{~h}$ (Table 4). At $12 \mathrm{~h}$, the expression of growth factors was up regulated (ctgf, hgf Jun b KLF12, fgt21, and Egr1).
The comparison of 3 and $12 \mathrm{~h}$ post ethanol bolus was also made, and the KEGG pathway of this comparison is shown in Fig. 8. The comparison of selected genes that changed in 3 and $12 \mathrm{~h}$ post ethanol bolus is shown in Table 5. The gene expression between 3 and $12 \mathrm{~h}$ was different. For instance, the gene expression of Egr1 was highly induced at $12 \mathrm{~h}$ compared to the $3 \mathrm{~h}$, and IL1r1 was highly induced at $3 \mathrm{~h}$ and decreased at $12 \mathrm{~h}$.

\section{Discussion}

In a review, Zakhari and $\mathrm{Li}$ [6] stated that "an understanding of the role of the quantity and frequency of alcohol consumed... is essential for appreciating both short-term and long-term effects of alcohol in liver pathogenesis..." They were referring to human alcoholic liver disease, but this kind of data is difficult, if not impossible, to obtain in humans. That is why rats fed a defined diet 


\section{2h EtOH v 3h EtOH}

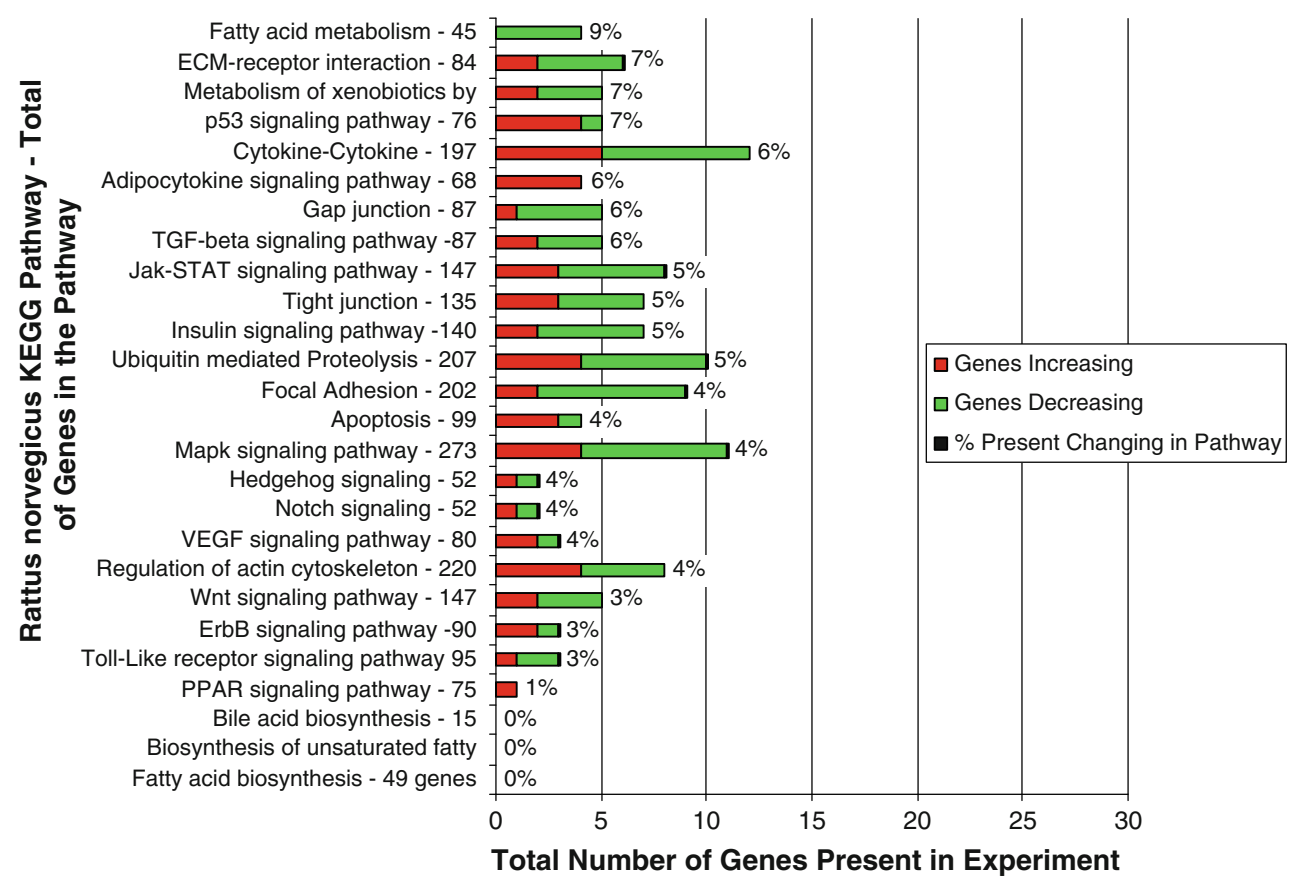

Fig. 8 KEGG functional pathways $12 \mathrm{~h}$ post ethanol bolus compared to the $3 \mathrm{~h}$ post ethanol bolus (Red up regulated, Green down regulated) $(n=3)$

Table 4 Comparison of fold changes post $12 \mathrm{~h}$ ethanol bolus and control $(n=3)$

\begin{tabular}{lrl}
\hline Gene symbol & Ratio & Gene name \\
\hline A2M & 48.84 & Alpha 2-macroglobulin \\
Egr1 & 13.09 & Early response gene \\
Igfbp7 & 10.78 & Insulin-like growth factor binding p \\
Lepr & 8.63 & Leptin receptor \\
Fgf21 & 5.78 & Fibroblastic growth factor-21 \\
Cxc11 & 3.34 & Chemokine legand 1 \\
Lbp & 3.29 & LPS binding protein \\
Foxa3 & 2.97 & Forkhead box A3 \\
Fabp4 & 2.87 & Fatty acid binding protein 4 \\
Klf12 & 2.35 & Kruppel-like factor 12 \\
Jun B & 1.72 & Jun B oncogene \\
Hspa9a & 2.08 & Heat shock 70 kDa protein 9A \\
HGF & 2.03 & Hepatocyte growth factor \\
Ctgf & 2.01 & Connective tissue growth factor \\
Mta2a & 2.01 & Methionine adenosyltransferase \\
Jak3 & 1.31 & Janus kinase 3 \\
Aldh1b1 & -1.61 & Aldehyde dehydrogenase 1 \\
Hdac11 & -3.07 & Histone deactylase 11 \\
Fasn & -3.18 & Fatty acid synthase \\
Gadd45g & -3.48 & Growth arrest and DNA damage 45c \\
Ubd & -3.81 & Ubiquitin D \\
Srebfl & -4.06 & Sterol regulator element bf1 \\
\hline
\end{tabular}

with pair feeding were used in the present study. The results reported here provide a large data base regarding changes in gene expression in a binge drinking model, previously compared with data from a chronic ethanol feeding model done when blood ethanol levels were either high or low [1]. The pattern of gene expression differed between the binge drinking and chronic ethanol feeding models. Here, it is shown that the pattern of gene expression varied between 3 and $12 \mathrm{~h}$ post ethanol gavage. These differences in gene expression changes can be changes appreciated when the KEGG functional pathways (Figs. 2 and 4) as well as changes in expression in individual genes are compared in Tables 2 and 4. Already published heat maps at 3 vs. $12 \mathrm{~h}$ as well as changes in the expression of genes at 3 and $12 \mathrm{~h}$ were compared [1]. The methyl donor, $S$-adenosylmethionine (SAMe), prevented the changes in gene expression at $3 \mathrm{~h}$, but not at $12 \mathrm{~h}$ post ethanol bolus, indicating that gene silencing induced by SAMe was transient. The results indicate that the gene expression programming induced by acute ethanol ingestion persisted for at least $12 \mathrm{~h}$.

In previous studies, no change in $\mathrm{H} 3 \mathrm{~K} 9 \mathrm{ac}, \mathrm{H} 3 \mathrm{~K} 18 \mathrm{ac}$, p300 (HAT), HDAC2, H3K4me2, or H3K27me3, at 3 and $12 \mathrm{~h}$ post ethanol bolus, was found [1]. Only the methylation of DNA was reduced at post $12 \mathrm{~h}$ post ethanol bolus [1]. Others have found that in an in vitro experiment where primary hepatocyte culture was exposed to 50 and $100 \mathrm{~mm}$ 
Table 5 Selected genes where the expression changed at 3 and $12 \mathrm{~h}$ post ethanol bolus

\begin{tabular}{|c|c|c|c|}
\hline \multirow[t]{2}{*}{ Gene title } & \multirow{2}{*}{$\begin{array}{l}\text { Gene } \\
\text { symbol }\end{array}$} & \multicolumn{2}{|l|}{ Ratio } \\
\hline & & $3 \mathrm{~h}$ & $12 \mathrm{~h}$ \\
\hline early growth response 1 & Egr1 & 2.51 & 13.09 \\
\hline insulin-like growth factor binding protein 1 & Igfbpl & 17.51 & 10.78 \\
\hline $\begin{array}{l}\text { S100 calcium binding protein AS } \\
\text { (calgranulin }\end{array}$ & S100a8 & 2.00 & 6.68 \\
\hline fibroblast growth factor 21 & Fgf21 & -1.96 & 5.78 \\
\hline chemokine (C-X-C motif) ligand 12 & Cxcl12 & 31.34 & 3.34 \\
\hline interleukin 1 receptor, type I & $111 \mathrm{r} 1$ & 1.54 & 3.32 \\
\hline FK506 binding protein 5 & FkbpS & 3.73 & 3.16 \\
\hline claudin 1 & Cldnl & 2.95 & 2.99 \\
\hline forkhead box A3 & Foxa3 & 1.95 & 2.97 \\
\hline $\begin{array}{l}\text { signal transducer and activator of } \\
\text { transcription }\end{array}$ & Stat3 & 3.46 & 2.71 \\
\hline cyclin-dependent kinase inhibitor $1 \mathrm{~A}$ & Cdknla & 6.45 & 2.45 \\
\hline Jun-B oncogene & Junb & 2.53 & 2.23 \\
\hline connective tissue growth factor & Ctgf & 2.46 & 2.01 \\
\hline transferrin receptor & Tfrc & 1.69 & 1.89 \\
\hline G protein-coupled receptor 116 & Gpr116 & 2.36 & 1.79 \\
\hline junction adhesion molecule 2 & Jam2 & 1.92 & 1.79 \\
\hline nuclear transcription factor-Y beta & Nfyb & -3.01 & 1.71 \\
\hline zinc finger protein $354 \mathrm{~A}$ & Zfp354a & 10.78 & 1.69 \\
\hline $\begin{array}{l}\text { protein tyrosine phosphatase, } \\
\text { receptor-type, }\end{array}$ & Ppfibp2 & -2.16 & -1.75 \\
\hline glutamate cysteine ligase, modifier subunit & Gclm & -1.85 & -2.01 \\
\hline Prostaglandin E receptor 3 (subtype EP3) & Ptger3 & -1.64 & -2.14 \\
\hline epidermal growth factor receptor & Egfr & 2.03 & -2.28 \\
\hline fatty acid synthase & Fasn & 2.13 & -3.18 \\
\hline D site albumin promoter binding protein & Dbp & -1.75 & -3.53 \\
\hline serine dehydratase & Sds & 3.66 & -4.41 \\
\hline stearoyl-Coenzyme A desaturase 1 & Scd 1 & 1.58 & -9.38 \\
\hline
\end{tabular}

of ethanol, $\mathrm{H} 3 \mathrm{~K} 9 \mathrm{me} 3$ was decreased and $\mathrm{H} 3 \mathrm{~K} 4 \mathrm{me} 3$ was increased [7]. These results differed from the data obtained on chronic ethanol fed rats where p300 was increased at peak blood alcohol levels, as was H3K9ac [2]. These results lead to the hypothesis that persistent epigenetic changes in gene expression only become manifest after chronic ethanol ingestion.

SAMe treatment effectively prevented the gene expression changes induced by the ethanol bolus at $3 \mathrm{~h}$, but not at $12 \mathrm{~h}$. SAMe, in fact, caused a marked global down regulation of gene expression only $3 \mathrm{~h}$ post ethanol bolus, but not at $12 \mathrm{~h}$ post ethanol bolus. This response suggests that SAMe methyl donor silencing of gene expression was short lived and was quickly reversed. This supports the concept that epigenetic changes in gene expression require chronic exposure before the changes are permanent.
SAMe treatment of drug primed mice prevented Mallory-Denk body (MDB) formation [8]. In that model, decreased trimethylation of $\mathrm{H} 3 \mathrm{~K} 9$ and $\mathrm{H} 3 \mathrm{~K} 4$ and methylation of DNA were related to changes in gene expression and MDB formation [5]. The changes in H3K9 and H3K4 were prevented by SAMe treatment, as were the changes in gene expression and MDB formation (5). The level of histone methyl transferase SUV39H1 that methylates H3K9 was reduced and SAMe also prevented this effect of the drug [5]. SAMe also prevented an increase in the level of the histone methyltransferase SET4/9 induced by the drug [5]. SET7/9 regulates the methylation of H3K4.

It is difficult to find hard evidence on the pharmacokinetics of SAMe in the liver in vivo. It is speculated that SAMe is unstable, whereas methylthioadenosine (MTA) derived from SAMe is not [9]. Treatment with SAMe doubles MTA and $S$-adenosyl-homocysteine (SAH) levels [9]. In vitro studies, where RAW cells were treated with different doses of SAMe, increased the levels of SAMe, MTA, and SAH in a dose dependent manner [9]. Extracellular culture media after $20 \mathrm{~h}$ of incubation retained $37 \%$ as SAMe and $27 \%$ as MTA [9].

In the case of the chronic ethanol-induced decrease in DNA and histone methylation, it is likely that these changes can be prevented by SAMe treatment [4]. Likewise, LPS toxicity increases binding of trimethylated $\mathrm{H} 3 \mathrm{~K} 4$ to the iNOS and TNF $\alpha$ promoter, and this is blocked by SAMe treatment by inhibiting the trimethylated H3K4 binding to their promoter response element. In this way, SAMe inhibits the proinflammatory response, which is seen in alcoholic liver disease [9, 10].

\section{References}

1. Bardag-Gorce F, French B, Li J, Dedes J, French SW (2009) Chronic Ethanol feeding alters hepatocyte memory which is not altered by acute feeding. Alcoholism Clin Exp Res 33:684-692

2. Bardag-Gorce F, French BA, Joyce M, Baires M, Montgomery RO, Li J, French SW (2007) Histone acetyltransferase p300 modulates gene expression in an epigenetic manner at high blood alcohol levels. Exp Mol Pathol 82:197-202

3. Oliva J, French BA, Li J, Bardag-Gorce F, Fu P, French SW (2008) Sirt is involved in energy metabolism. The role of chronic ethanol feeding and resveratrol. Exp Mol Pathol 85:155-159

4. Shukla SD, Velazquez J, French SW, Lu SC, Ticku MK, Zakhari $S$ (2008) Emerging role of epigenetic in the actions of alcohol. Alcoholism Clin Exp Res 32:525-1534

5. Bardag-Gorce F, Oliva J, Villegas J, Fraley S, Amidi F, Li J, Dedes J, French B, French SW (2008) Epigenetic mechanisms regulate Mallory Denk body formation in the livers of drugprimed mice. Exp Mol Pathol 84:113-121

6. Zakhari S, Li T-K (2007) Determinants of alcohol use and abuse: Impact of quality and frequency patterns on liver disease. Hepathology 46:2032-2039 
7. Pal-Bhadra M, Bhadra U, Jackson DE, Mamatha L, Park P, Shukla SD (2007) Ethanol and chromatin remodeling histone H3 methylation at lys-4 and lys-9 correlates with up and down regulation of genes in rat hepatocytes. Alcoholism Clin Exp Res $31: 13 \mathrm{~A}$

8. Li J, Bardag-Gorce F, Dedes J, French BA, Amidi F, Oliva J, French SW (2008) $S$-adenosylmethionine prevents Mallory Denk body formation in drug-primed mice by inhibiting the epigenetic memory. Hepatology 47:613-624
9. Ara AI, Xia M, Ramani K, Mato JM, Lu SC (2008) S-adenosylmethionine inhibits lipopolysaccharide-induced gene expression via modulation of histone methylation. Hepatology 47:16551666

10. Gobyishvilli L, Barve S, Joshi-Barve S, Uriarte S, Song Z, McClain C (2006) Chronic ethanol-mediated decrease in cAMP primers macrophages to enhanced LPS-inducible NF- $\kappa \mathrm{B}$ activity and TNF expression: relevance to alcoholic liver disease. Am J Physiol Gastrointest Liver Physiol 291:G681-G888 